\title{
PREFACE
}

When we began work on our previous volume, Pioneer Photographers of the Far West: A Biographical Dictionary, 1840-1865, we envisioned it as a study of early California photography. It was to have been a one-off book - a pastime to fill up those long winter nights for a few years. As the manuscript took shape, it seemed to develop a life and mind of its own. An urgent need to expand eastward-Manifest Destiny in reverse, if you will—seemed to be part of its nature. Ultimately, the book covered much more territory than just California. The logic and inevitability of writing a follow-up volume covering the "rest of the West" from the Mississippi River to the Rocky Mountains became increasingly manifest.

The creation of the work before you has proved to be much easier in certain respects than in the previous volume, and much harder in other ways. Devising the format of the biographical entries in the first volume was a time-consuming, trial-and-error process which we did not have to repeat this time. Also, this book was written with the full benefit of the internet, making communications and much of the research faster and simpler than before. On the debit side, certain research materials, particularly newspaper files for several states, proved difficult to locate and access. The sheer mass of photographers active in our study area complicated the task of delving deeply into the story of each person. Yet, as our acknowledgments attest, a number of colleagues made our task easier by offering us generous assistance.

\section{PROFESSIONAL SCOPE}

The principal theme of this series is the lives of daguerreotypists, ambrotypists, and photographers. We also cover other trades and professions with close links to photography. These include suppliers to the photographic trade; gallery employees; photographic overpainters, retouchers, and printers; and dealers and distributors of photographic prints.

Also discussed are artists with links to the photographic arts. This includes a select group of engravers and lithographers who based their works on photographic originals. We also included artists, staff, and proprietors of moving panoramas and other largeformat pictorial entertainments, such as cosmoramas, dioramas, stereopticons, and magic lanterns.

A special professional category is "Artist" (in quotation marks). This refers to any worker who was specifically referred to as "artist" in censuses, city directories, and other primary references, and whose precise professional specialty is unknown. "Artists" appear in this work because daguerreians and photographers often referred to themselves as such. 
All "artists" have been checked against standard sources on painters, printmakers, and photographers. Those who have been found to be outside of the professional parameters of this study have been eliminated.

This book contains a separate section on anonymous photographers. Usually these entries are derived from anecdotal accounts or advertisements in which specific names were not mentioned, or from dated images from a location where no identified photographers were working at that time. Some of the "anonymous" workers may in fact have been well-known figures.

\section{GEOGRAPHICAL AND TIME PARAMETERS}

This work covers the United States from the Mississippi River west to the states included in the previous volume, Pioneer Photographers of the Far West: A Biographical Dictionary, 1840-1865. Included are North Dakota, South Dakota, Minnesota, Iowa, Nebraska, Missouri, Kansas, Arkansas, Oklahoma, Louisiana, and Texas. In Canada, this book includes the present-day provinces of Manitoba and Saskatchewan. All of Mexico is included save the following: Baja California, a strip approximately one hundred miles east of the Pacific Coast, and the Yucatán Peninsula, all of which were covered in the previous volume. Selected artists based outside of the study area who painted moving panoramas with subjects relevant to the geographical scope of this volume are included.

The biographies in this work include persons who began working in the study area before January 1,1866 . Notwithstanding that termination date, full attention is given to their post-1865 work whenever possible. Persons who were included in Pioneer Photographers of the Far West but were also active in the area covered in this book receive entries herein.

\section{SOURCES}

We have resorted to many of the standard tools of photo-historians in compiling this work: city directories and state gazetteers, photographic imprints, newspaper advertisements and articles, county histories, and census records. We have consulted original Internal Revenue tax lists as well as utilized the results of Ross J. Kelbaugh's tax list research, as published in his Directory of Civil War Photographers, vol. 3, Western States and Territories, 2d ed. (Baltimore: Historic Graphics, 1992). We have reviewed censuses for all of the U.S. states and territories covered in this book. In some cases, we screened all counties of a given state for the census years 1850 and 1860. In other cases, the census searching has been more selective, for various reasons. Some counties were so sparsely populated or skewed to agriculture to the exclusion of other occupations that searching for photographers would be fruitless. Census microfilm for many Louisiana parishes proved to be so poorly filmed as to be virtually unreadable. Significantly, many of these substandard reels are marked as being derived from "best copy available" of the original census records. 


\section{ILLUSTRATIONS}

All photographs in this book not specifically credited are from the Peter E. Palmquist Collection, Beinecke Rare Book and Manuscript Library, Yale University, New Haven, Connecticut.

\section{A POSTSCRIPT BY THOMAS R. KAILBOURN}

On Saturday, January 11, 2003, Peter E. Palmquist sent me an e-mail approving the final revisions of the captions for this book, thus effectively concluding work on the manuscript. He expressed his wish for his dedication of the book to be to his brothers, wrote of his and Pam Mendelsohn's upcoming wedding celebration and my plans to attend, and mentioned that "I am leaving shortly for the Bay Area and will be back on Thursday." That evening, after arriving at Pam's apartment in Emeryville, California, Peter was killed by a hit-andrun driver.

Peter lived an extremely useful life. He was generous with information and good advice, and he delighted in encouraging new talent. The more than 60 books and 340 articles he published only begin to suggest what an indefatigable human dynamo he was. His home in Arcata, California, was virtually a one-man mini-college campus, where scholars and collectors were welcome to come and use his vast research collections.

Peter said if you learned to "follow your nose," you would accomplish great things in research. Although at times it seemed as if he was tuned in to some great, open channel to the secrets of photographers past, certain nagging mysteries eluded his solution. He didn't live long enough to discover, as he had hoped, what really happened to Robert H. Vance's "Lost 300" daguerreotypes, but he filled in far more than his share of the mosaic we photohistorians continue to work on.

While all too many researchers have held tight to their discoveries even to their graves, Peter understood that we advance knowledge only by interacting and sharing what we know. To ensure that his work will long continue to benefit scholars, Peter saw to it that his research and photographic collections will be preserved at the Beinecke Rare Book and Manuscript Library at Yale University.

I shall miss Peter's cheerful presence and unflagging energy. His sense of humor helped me through many difficult periods. During one particularly grueling writing project, he asked me, "Do you hate that manuscript yet?" "Yes," I admitted. "Good," he chuckled, "that always means you're at least half-way finished!"

Although Peter is no longer with us physically, his work and shining examples will live on. Future historians will learn to their delight that he left for them many guideposts and roadmaps to the writing of photo history. 


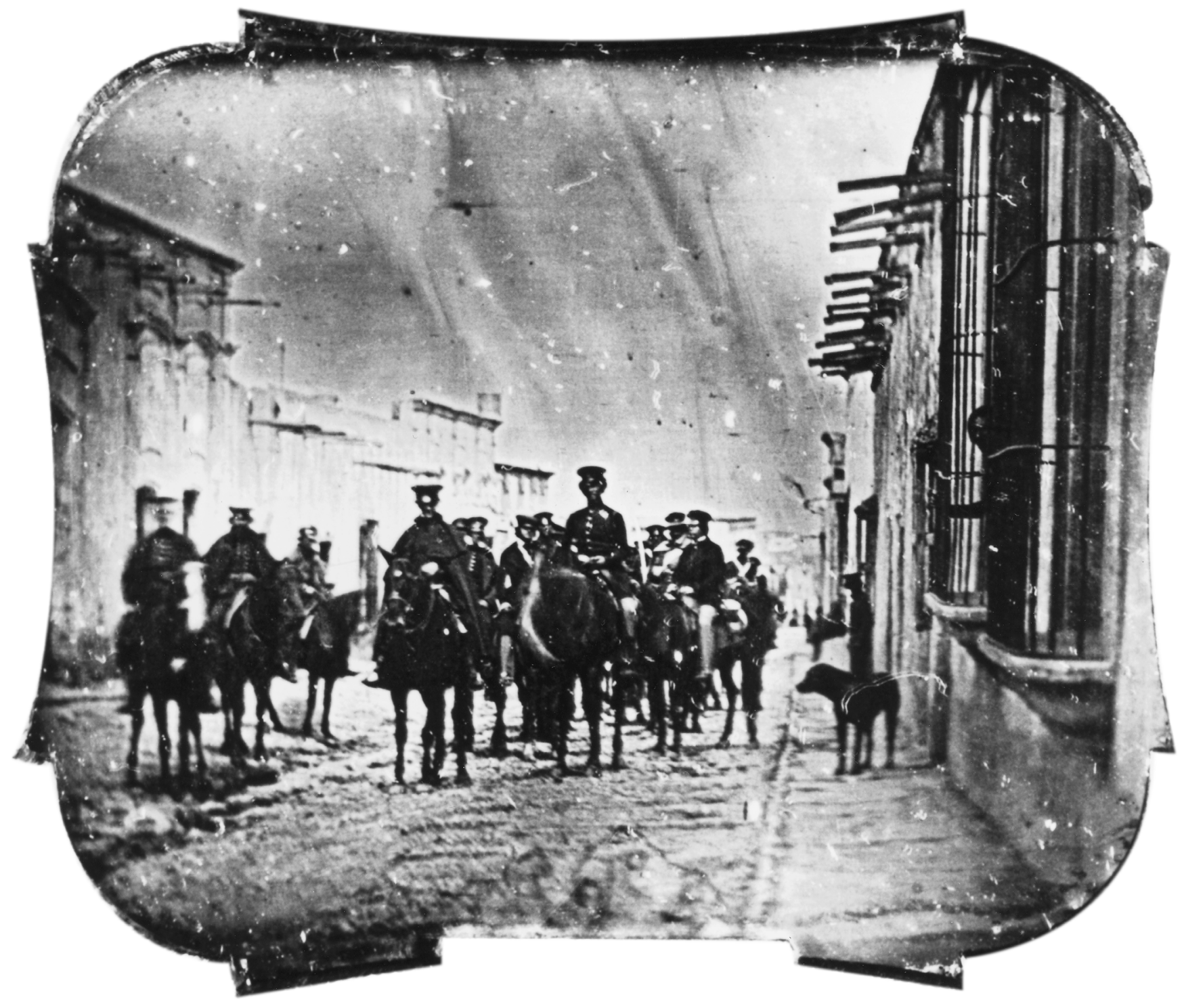

Fig. 4. Genl. Wool \& Staff/Calle Real to South, Saltillo, Mexico. Sixth-plate daguerreotype, unknown maker, c. 1847. (Beinecke Rare Book and Manuscript Library, Yale University) 